\title{
Application and Exploration of Virtual Simulation Technology in Practice Teaching of Local Colleges and Universities
}

\author{
Li Dai ${ }^{1, *}$ and Yuke Yang ${ }^{2}$ \\ ${ }^{1}$ Teaching Affair Office, Leshan Normal University, Leshan, China \\ ${ }^{2}$ Teaching Affair Office, The Engineering \& Technology College of Chengdu University of Technology Leshan, China \\ ${ }^{*}$ Corresponding author. Email: 542238026@qq.com
}

\begin{abstract}
Ascribe to integration of virtual reality, interactive experience, computer graphics and other related technologies, virtual simulation has been widely utilized in the practice teaching of local colleges and universities. Especially, its construction and development in experimental teaching have been acknowledged as an important measure in the informationalized construction of practical teaching in colleges and universities. Herein, in view of the defects and shortcomings of traditional practice teaching in local colleges and universities, the construction ideas of virtual simulation experimental teaching was proposed, centering on the connotation of virtual simulation experimental teaching. And then, the effective approaches were discussed about virtual simulation technology application in practice teaching in colleges and universities from the aspects of hardware and software.
\end{abstract}

Keywords: Virtual simulation, Experimental teaching, Informationalized construction.

\section{INTRODUCTION}

Practical teaching, as an important supplement to theoretical teaching, played a significant and indispensable role in colleges and universities. However, due to the limitation of many objective conditions, the concept, content and mode of traditional practical teaching cannot meet the development of the society and the discipline and specialty. In recent years, The Ministry of Education has issued many documents such as "Education Informatization Decade Development Plan (2011-2020)", "Education Informatization 2.0 Plan" and so on. These documents require that colleges and universities should continue to promote the construction of experimental teaching informatization, and strengthen the construction and application of high-quality experimental teaching resources, and accelerate the reform and innovation of experimental teaching. Virtual simulation technology refers to the product of modern information technology, while virtual simulation experiment teaching in colleges and universities refers to the deep integration of modern information technology and experiment teaching. And its aim is to solve the defects and shortcomings of traditional practice teaching effectively and to improve the quality of practice teaching and the level of practice education. Based on the connotation of virtual simulation technology and virtual simulation experiment teaching, the effective application of virtual simulation technology in practical teaching was discussed, aiming at the problems existing in the practice teaching of local colleges and universities.

\section{PRESENT SITUATION OF PRACTICE TEACHING IN LOCAL UNIVERSITIES}

Practical teaching combines subject theoretical knowledge with practical skills closely, which is an important part of teaching in colleges and universities and an important means to cultivate students' practical innovation ability. At present, with the increasing demand of practical innovation ability of society, most colleges and universities have paid increasing attention to the implementation of students' practical teaching. However, due to the restriction of teaching concepts, practical teaching conditions, practical teaching mode and content, the practical teaching in local colleges and universities seems unsatisfactory. Traditional teaching in China has been deeply rooted for long, and colleges and universities have attached importance to theoretical teaching timelessly, consequently, practical teaching has 
been still situated in a subordinate position. In teaching processes, the explanation of theoretical knowledge has received rather more attention than the development and implementation of practical teaching. The teaching idea that theory was attached more importance than practical in Chinese traditional teaching has led to students' lack of practical knowledge and of practical innovation ability. However, theory is apt to be abstract, while practice more focuses on the concrete matters. Only through undergoing practical teaching could students acquire and master the abstract theoretical knowledge better. It is when students truly turn knowledge from various books into their own that they can flexibly exert themselves ultimately to solve problems encountered in practical life [1].

The practical teaching conditions, such as sufficient places, complete supporting facilities, advanced equipment and so on, are the essential ones to implement the practical teaching and run its experimental projects, which directly affect the effect of practical teaching. However, due to the shortage of funds or the influence of other objective factors in most universities, practical teaching has always been unable to meet the development of professional disciplines, especially in the implementation of the science and engineering experimental teaching. Problems of lacking and incomplete equipment or its poor performance has persisted generally. In recent years, the structure of academic disciplines has been in constant adjustment, and furthermore, the interactional combinations between disciplines has been getting deeper and broader. Nevertheless, failing to obtain supplement and update in time, the practical teaching contents were lack of comprehensiveness and innovativeness, and this has resulted in a single practice teaching mode. Replication and demonstrative experiments in science and engineering were usually taken for an example. Presently, the practical teaching methods have caused the students to operate experiments only according to teachers' guidance, and this could deprive students of the opportunities for independent thinking and hands-on operating experiments. Furthermore, various shortcomings laying current experiment teaching content, it is fairly difficult for students to acquire experimental skills systematically and completely, and their capacities of comprehensive analysis and innovative design have still located deficiently [2].

\section{CONNOTATION OF VIRTUAL SIMULATION EXPERIMENTAL TEACHING}

Virtual simulation technology can provide highly restored simulation system and promote increasing applications in experimental teaching, benefitting from its characters of interactivity, immersion and conception. Those applications would reduce the cost effectively, improve the efficiency greatly and optimize the quality fairly in experimental teaching processes [3].As a deep integration between modern information technologies and experimental teaching projects, virtual simulation experimental teaching could overcome the traditional experimental teaching shortcomings of higher cost, lower security and poorer efficiency, and facilitate experimental teaching get more intuitive and systematic [4].Virtual simulation experimental teaching refers to the virtual reality (VR), simulation, computer image processing and other modern information technologies. It aims to solve the problems of unavailable experimental conditions, actual operation difficulties, high-risk involvement or extreme environments, and promotes the development of the reform of experimental teaching of institutions of higher learning, and focuses on cultivating the students' practical ability to innovate.

Virtual simulation experimental teaching adheres to the student-centered and endows students with subjectivity adequately. In specific simulation processes, starting from the needs of students, solving problems as an orientation, to meet the requirements and to complete contents in experimental teaching processes, it refers to the comprehensive utilization of multimedia, big data, artificial intelligence, virtual reality and other technologies, and creates experimental teaching scenes and simulates the interaction experience. It also concentrates on case learning with interaction, discussion and investigation, in students' favor of being immersive to found and analyze problems, and to carry on practical operations. Thus, students' interests would be fully stimulated and their innovation practice abilities would be improved greatly. Virtual simulation experiment teaching is a new mode of experiment teaching which combines online and offline. Online construction and development of the virtual simulation experimental teaching platform refers to the application of digital resource system and the innovative researches, and could better service for that of disciplines. While, offline teaching mode is related to the construction and modification of hardware environment through virtual reality technology, so as to adapt to the development of various disciplines in practical teaching processes.

\section{CONSTRUCTION OF VIRTUAL SIMULATION EXPERIMENTAL TEACHING}

\subsection{Establishment of Learning Rooms for General Virtual Simulation}

At present, part of the general education courses with strong theory offered by colleges and universities have been incapable of taking students to visit or experience the practical teaching section due to the 
limited practical training places provided by the society or enterprises and the restriction of time, space and region etc. . The lack of practical training contents led to students' inability to deeply understand relevant theoretical knowledge and lack of interest in learning, and this would lead to poor teaching effects of such courses. Fortunately, virtual reality and other modern information technologies equipped with LED3D arc screen, optical positioning system, teaching computer, data gloves and movable tables and chairs, an offline virtual simulation learning platforms that can accommodate 50-60 people, could be employed for colleges and universities to solve such problems. Functions for virtual simulation centralized teaching, VR experience, conference, and lecture, visit etc. can be realized by use of the virtual simulation learning rooms, in line with the needs of guided, open and other multimode. Teachers' interactive operation in the learning rooms can be conducted through two modes of data gloves and VR handles. For example, in the instruction of ideological and political courses, virtual simulation technology integrated with traditional teaching modes, highly restored historical scenes of the red period from visual, auditory, tactile and other sensory aspects, so that students can immerse themselves, enrich the learning experiences, realize the absorption of knowledge, and thus strengthen the understanding of theoretical knowledge.

\subsection{Establishment of Training Rooms for Professional Virtual Simulation}

For professions with pragmaticality and vulnerability to laboratory equipment, sites, investigated objects, and many other objective factors in the traditional experiment, building offline virtual simulation training rooms for 25 to 30 students, and grouping to interact virtually and really can effectively crack bottleneck that the traditional experimental teaching is difficult to solve. Professional virtual simulation training rooms, equipped with VR computers, VR headsets, gestures motion-sensing controllers, MR (mixed reality) helmets and virtual simulation platforms of walking devices and movable desks and chairs, can integrate virtual simulation of autonomous learning, developing and experiencing VR and $\mathrm{MR}$, to meet the requirement of the professional disciplines and multi-disciplinary teaching and application. The virtual simulation system uses threedimensional imaging technology of real-time perception to construct the experiment process in a virtual situation, so as to provide students with a learning environment simulating the real situation, intuitively present knowledge to students through human-machine equipment, and help students to understand and master relevant knowledge [5]. Taken for an example, biological and chemical experimental teachings in colleges and universities, due to toxicities of some reagent drugs, safety of experimental instruments' operations, limited time, animals' aggression and the complexity of the field environment, the actual operation risks really exist in the experimental teaching processes. In view of circumstances above, the risks of experimental operations for students could be reduced dramatically through repeatedly practicing safe simulation experiment in the virtual simulation training rooms, to raise the experiment safety awareness and consciousness of correct operation.

\subsection{Construction of Virtual Simulation Experimental Teaching Platforms}

Information technology resources are an important part of practical teaching in colleges and universities. In order to meet the urgent demand of some professions for virtual simulation teaching, colleges and universities can adopt the construction idea of combining procurement and customization, introduce some virtual simulation experimental teaching projects and build virtual simulation experimental teaching resource platform. Virtual simulation software resources based on real scenes, tasks, processes, methods and data, refers to special education, chemical engineering, biotechnology and other majors. Teachers and students both can log in the virtual simulation experiment teaching platforms, experience virtual simulation online, and utilize information technology extremely.

"Virtual Simulation Experiment for Teacher Training to Rehabilitate Autistic Children Education" in special education was taken for an example, with comprehensive utilization of the network platforms and 3D modeling software, human-computer interaction, animation and other modern information technology. Consequently, restrictions from practical ethics, unsatisfying effects in teaching processes will be broken through and the shortage of talents against autism will be covered, immersing themselves in the simulation scene through the virtual simulation experiment, and really experiencing characteristics of children with autism behavior corresponding with the response and solution of problems.

"Virtual Simulation Experiment for Formation and Control of Typical Material Defect and Preparation of Monocrystalline Silicon Ingots" in material class majors was another example. Online sharing of virtual simulation experiments was realized through WebGL technology, and does Web interactive virtual simulation experiments through HTML scripts, so as to access and operate virtual simulation experiments in browsers without plug-ins. 


\subsection{Construction of virtual simulation software developing platforms}

The virtual simulation experimental teaching resources introduced from multiple channels meet the experimental teaching needs of some disciplines and specialties in a short term, but the software content has some problems, such as disconnection with the actual needs or failure to modify and upgrade the software in the later use.

In view of the phenomenon of "last mile" and "onetime development" existing in current virtual simulation projects, colleges and universities can build a virtual simulation software developing platform through the virtual simulation developing engines and make use of the available training rooms and computer resources to effectively solve the sustainable problems of project construction.

Virtual simulation software developing engines can be built on Unity3D technology and its platforms of the rapid development for teaching simulation software to optimize and upgrade should be constructed. With characters of use of excel text language, easy to learn, dispensable to master a programming language for developers, needlessness of professional technical background, the platform can be utilized innovatively to improve the efficiency of virtual simulation software development and to reduce development threshold and development costs.

In the process of the development or upgradation of virtual simulation software in colleges and universities, according to the set situation of subjects, the application of virtual simulation engines should combine with subjects such as artificial intelligence, computer digital media etc.. The whole professional students should carry on the simulation software modeling design, and moreover, students that have mastered the exploitation of the software should proceed function and interaction designing. The situation of "virtual reality, and all development" could be gradually realized though the team cooperation to develop more novel and professional VR software, so as to push forward construction of the informationized experimental teaching and to enrich students' imagination and creativity.

\section{CONCLUSION}

Virtual simulation technology integrates virtual reality and simulation experience, which has good immersion, interaction and fidelity.
The virtual simulation technology is introduced into the practical teaching of colleges and universities, by use of online and offline and by means of combination of the hardware and software. And it refers to the construction of general virtual simulation labs, professional virtual simulation training rooms, virtual simulation experiment teaching platforms and software development platforms, which can effectively cover the shortage of insufficient and incomplete equipment in the traditional practical teaching processes, and solve the problems of resource level's unicity, and the difficulties to carry out practical training.

By constructing virtual simulation experiment teaching environment and introducing and exploiting virtual simulation project software resources, to extend the experiment teaching from aspects in space and time, the breadth and depth of the experiment teaching contents will be expanded dramatically. With local universities' experiment teaching idea gradually into the one with students as the center, promoting experiment teaching reform and innovation, the students' practical ability to innovate will be enhanced greatly as an extreme ultimate aim.

\section{REFERENCES}

[1] Lu Yunxia. Analysis and Discussion on the Current Situation of Experimental Teaching Processes in Colleges and Universities [J]. Journal of Higher Education, 2015(21):224-225. (In Chinese)

[2] Ma Linyuan. A Brief Analysis of the Development Status and Improvement Methods of Experimental Teaching in Colleges and Universities [J]. Intelligence, 2017(09):107-108. (In Chinese)

[3] WANG C. Application exploration of virtual simulation technology in middle school chemistry experiment teaching $[\mathrm{J}]$. Education and Equipment Research, 2020, 36 (12). (In Chinese)

[4] Wang Rui, Li Qi, Jiang Zhenglong, Liu Changfeng.Construction of Virtual Simulation Experiment Teaching Platform for Marine Geology [J]. Experimental Technology and Management 2020(12):250-252. (In Chinese)

[5] Zhong Yi, Zheng Yangyu, Song Xiaoling et al.Application of digital section of oral histomathology based on virtual simulation experimental teaching platform $[\mathrm{J}]$.Chinese Journal of Higher Medical Education, 2019 (6) : 3-4. (In Chinese) 